\title{
The difference of Reticulocyte Hemoglobin Equivalent Pre- and Post-Ultrafiltration Hemodialysis in Patients with Chronic Kidney Disease
}

\author{
Ni Made Rindra Hermawathi ${ }^{1}$, Arifoel Hajat ${ }^{1}$, Yetti Hernaningsih ${ }^{1}$, Widodo ${ }^{2}$ \\ ${ }^{1}$ Department of Clinical Pathology, Faculty of Medicine, Airlangga University/Dr. Soetomo Hospital in Surabaya, Indonesia. E-mail: \\ herma_md@yahoo.com \\ ${ }^{2}$ Department of Internal Medicine, Faculty of Medicine, Airlangga University/Dr. Soetomo Hospital, Surabaya, Indonesia
}

\begin{abstract}
Chronic Kidney Disease (CKD) is a condition characterized by kidney damage and a decrease of Glomerular Filtration Rate of less than $60 \mathrm{~mL} / \mathrm{min} / 1.73 \mathrm{~m}^{2}$ in more than three months. Anemia is the most common complication in patients with CKD who regularly undergo hemodialysis. Reticulocyte Hemoglobin Equivalent (Ret-He) is a new parameter that can reflect the storage of iron for erythropoiesis. This study compared the Ret-He level pre and post-hemodialysis and evaluated the effect of ultrafiltration (UF) hemodialysis to Ret-He level in CKD patients. This research was an observational analytical study. Samples were 50 patients with CKD who underwent hemodialysis regularly in Dr. Soetomo Hospital Surabaya by consecutive sampling from August-September 2017. The measurement of the Ret-He level pre ultrafiltration hemodialysis was divided into UF $<2 \mathrm{~L}$ and UF $\geq 2 \mathrm{~L}$. Both groups showed homogenous results. The group with UF $<2 \mathrm{~L}$ increased significantly from pre to post ultrafiltration ( $p=0.010$ ). The group with $U F \geq 2 L$ was not increased considerably from $30.57 \pm 3.62$ to $32.69 \pm 3.45$ ( $p=0.413$ ). Ret-He level in the group with UF $<2$ L was $0.81 \pm 1.10$, significantly higher than the group with UF $\geq 2 \mathrm{~L} 0.12 \pm 0.83$ ( $p=0.017$ ). The difference of Ret-He level pre and post ultrafiltration was significant in UF $<2 \mathrm{~L}$. There was a significant increase of the RetHe level in hemodialysis with UF $<2 \mathrm{~L}$ compared to UF $\geq 2 \mathrm{~L}$. The measurement of Ret-He should be performed before hemodialysis due to an increase in Ret-He after ultrafiltration hemodialysis.
\end{abstract}

Keywords: Ret-He, ultrafiltration, chronic kidney disease

\section{INTRODUCTION}

Chronic Kidney Disease (CKD) is damage to the kidneys or reduced Glomerular Filtration Rate (GFR) < $60 \mathrm{~mL} / \mathrm{min} / 1.73 \mathrm{~m}^{2}$ for over three months based on the Indonesia Renal Registry (IRR) the prevalence of chronic kidney disease increases every year. ${ }^{1}$ According to the National Kidney Foundation-Kidney Disease Outcomes Quality Initiative (NKF-KDOQI) 2006, anemia in CKD occurs when the hemoglobin level is $<13.5 \mathrm{~g} / \mathrm{dL}$ in males and $<12.0 \mathrm{~g} / \mathrm{dL}$ in females. ${ }^{2-4}$ Anemia is a common complication in patients with CKD, especially in patients with regular hemodialysis. The leading cause of anemia in this group is the number of inadequate endogenous erythropoiesis and also iron deficiency anemia. ${ }^{5}$ Some international guidelines, such as the European Best Practice Guidelines and the United States Kidney Disease Outcome Quality Initiative, suggest using conventional biochemical markers such as ferritin and Serum Transferrin Saturation (TSAT) in iron deficiency anemia. Reticulocyte Hemoglobin
Equivalent $(\mathrm{RET}-\mathrm{He})$ is a new parameter reflecting the availability of iron used for the process of erythropoiesis in the bone marrow. Reticulocytes show a rapid succession in circulation compared with the mature erythrocytes. It is estimated that reticulocytes are more sensitive in detecting the activity of erythropoiesis. ${ }^{6}$ The management of patients with CKD who reached the terminal stage (CKD stage 5 ) is a renal replacement therapy such as hemodialysis (HD), Peritoneal Dialysis (PD), and a kidney transplant. ${ }^{1}$ Diffusion process occurs during hemodialysis and ultrafiltration. The diffusion process is the movement of molecules across the membrane of the region with a high solute concentration to the area with a low salute concentration. Waste products such as urea and creatinine with high levels move from the blood to the dialysate fluid. Bicarbonate and acetate in the dialysate will be absorbed in the blood and improve the blood acidity. The dialysate around capillary blood containing waste products will be replaced by fresh dialysate with a $500-800 \mathrm{~mL} / \mathrm{min}$ speed. 
Ultrafiltration rate is the rate of fluid removal during hemodialysis. It has been put forward as a potential actionable component of fluid management. ${ }^{7}$ Hemodialysis process often results in iron deficiency anemia. RET-He parameter is used to show the availability of iron in the bone marrow to be used for hemoglobin synthesis. ${ }^{8.9}$ This research was done because there was no previous research in Indonesia about the levels of Ret-He before and after hemodialysis. This research was also performed to see whether there was an influence of the ultrafiltration hemodialysis process to Ret-He levels in patients with chronic kidney disease.

\section{METHODS}

This research was an observational analytical study conducted at Dr. Soetomo Hospital in Surabaya, Indonesia. The study subjects who met the inclusion criteria were consecutively assigned. The subjects included were Outpatient Clinic patients of the Department of Internal Medicine in the hemodialysis room from August 2017 to September 2017.

This study was conducted in 50 CKD patients who underwent regular hemodialysis at the Dr. Soetomo Hospital Surabaya and who had filled out an informed consent. Inclusion criteria in this study were CKD patients who had undergone hemodialysis 2-3x/week for at least two months and CKD patients who had undergone hemodialysis $\geq 4$ hours. This research divided the patients into two groups. The first group comprised patients with ultrafiltration hemodialysis less than $2 \mathrm{~L}$. The other patient's group had ultrafiltration hemodialysis $>2 \mathrm{~L}$, based on the therapeutic protocol given in the Department Internal Medicine of Dr. Soetomo Hospital, Surabaya. The exclusion criteria were patients undergoing transfusion during hemodialysis, CKD patients with bleeding, clots found in the blood sample, and the existence of lump on the dialysis membrane.

The subjects that fulfilled the inclusion criteria were examined for Ret-He. Three $\mathrm{mL}$ of venous blood samples were taken in EDTA tubes. Then routine hematological examinations were performed by activating reticulocyte mode with Sysmex XN 1000.

This research had received approval from the Health Research Ethics Committee of the Dr. Soetomo Hospital Surabaya with number 436/Panke.KKE/VII/2017. Research subjects who followed the study signed a letter of approval. The study results were statistically analyzed with SPSS
20.0, using a frequency distribution table, to examine differences in the characteristics of respondents with numerical data scales. The distribution of the data in this research was normal (homogeneous); therefore, the data were calculated by a T-paired test. A value of $p<0.05$ was considered a significant result.

\section{RESULT AND DISCUSSION}

The study subjects were 50 patients consisting of 25 males and 25 females (Table 1 ).

Table 1. Characteristic of patients on gender and age

\begin{tabular}{cc}
\hline Profile & Result \\
\hline Gender & \\
Male & $25(50 \%)$ \\
Female & $25(50 \%)$ \\
Age & \\
Range & $20-74$ \\
Mean $/ x \pm S D$ & $49.71 \pm 11.25$ \\
\hline
\end{tabular}

In this study, Ret-He levels were measured before ultrafiltration hemodialysis was performed to determine that the Ret-He levels before treatment between the two test groups were homogeneous. The group with ultrafiltration $<2 \mathrm{~L}$ comprised as many as 16 people with Ret-He levels of $31.19 \pm 2.47$ and the group with ultrafiltration of $\geq 2 \mathrm{~L}$ as many as 34 people and Ret-He levels of $30.57 \pm 3.62$ with $p=0.535$. The two groups showed results that were not much different, meaning that both groups were homogeneous before hemodialysis ultrafiltration (Table 2).

Table 2. Ret-He pre-ultrafiltration hemodialysis

\begin{tabular}{lccc}
\hline Variable & $\begin{array}{c}\mathbf{U F}<\mathbf{2} \mathbf{L} \\
\mathbf{N}=\mathbf{1 6}\end{array}$ & $\begin{array}{c}\mathbf{U F}=\mathbf{2 L} \\
\mathbf{N}=\mathbf{3 4}\end{array}$ & $\mathbf{P}$ \\
\hline Ret-He & $31.19 \pm 2.47$ & $30.57 \pm 3.62$ & 0.535 \\
\hline
\end{tabular}

This research was a different test of two groups and used a parametric paired sample T-test because these two groups were usually distributed (homogeneous). The results of the Ret-He test before and after ultrafiltration hemodialysis can be seen in Table 3.

Table 3. Ret-He pre- and post-ultrafiltration $<2 \mathrm{~L}$ and $\geq 2 \mathrm{~L}$

\begin{tabular}{cccc}
\hline Ultrafiltration & Pre & Post & P \\
\hline$<2 \mathrm{~L}$ & $31.19 \pm 2.47$ & $32.00 \pm 2.49$ & 0.010 \\
$\geq 2 \mathrm{~L}$ & $30.57 \pm 3.62$ & $30.69 \pm 3.45$ & 0.413 \\
\hline
\end{tabular}


There was an increase in Ret-He levels from $31.19 \pm 2.47$ to $32.00 \pm 2.49$ after ultrafiltration hemodialysis in the ultrafiltration group $<2 \mathrm{~L}$ $(p=0.010)$. In the ultrafiltration group $\geq 2 \mathrm{~L}$, there was an increase in Ret-He levels from $30.57 \pm 3.62$ to $32.69 \pm 3.45$ after ultrafiltration hemodialysis $(p=0.413)$. The results of testing the differences in Ret-He levels after ultrafiltration $<2 \mathrm{~L}$ and $\geq 2 \mathrm{~L}$ can be seen in Table 4.

Table 4. The differences Ret-He post-ultrafiltration $<2 \mathrm{~L}$ and $\geq 2 \mathrm{~L}$

\begin{tabular}{lccc}
\hline Delta & UF $<\mathbf{2}$ L & UF $\geq \mathbf{2 L}$ & $\mathbf{P}$ \\
\hline Ret-He & $0.81 \pm 1.10$ & $0.12 \pm 0.83$ & 0.017 \\
\hline
\end{tabular}

Based on the test results, it was found that the Ret-He level in the group with ultrafiltration $<2 \mathrm{~L}$ was $0.81 \pm 1.10$ higher than the group with ultrafiltration $\geq 2 \mathrm{~L}$ by $0.12 \pm 0.83$ and this difference was said to be significant with $\mathrm{p}=0.017$.

In CKD patients with hemodialysis therapy, iron deficiency anemia is often found, which can be established by examining serum iron, total iron-binding capacity, and ferritin. However, the examination of serum ferritin and transferrin saturation was influenced by an inflammatory process that will affect the patient's iron status, so a stable alternative parameter was sought to assess iron status in CKD patients with hemodialysis. One new parameter was reticulocyte hemoglobin content or reticulocyte hemoglobin content $(\mathrm{CHr})$ which described the iron content in reticulocytes. ${ }^{2}$

A study by Frank et al. showed a good relationship between Ret-He and $\mathrm{CHr}$. Ret-He, which can be measured with an existing hematology instrument using XE RET master software. ${ }^{10}$ In Indonesia, measurement of the Ret-He parameter can be done simultaneously with a complete blood count check. ${ }^{5}$

Dalimunthe's research stated that Ret-He was the earliest marker of iron deficiency anemia and an early marker of the response of intravenous iron therapy in patients with routine hemodialysis. Ret-He measurements could be done within four weeks after administration of more initial intravenous iron therapy when compared with serum ferritin parameters and serum transferrin saturation which should be measured within three months after the administration of therapy. ${ }^{5}$

In the Ret-He examination in CKD patients with hemodialysis, attention has to be paid to the time of the study. In the process of hemodialysis, the determination of ultrafiltration was related to the ultrafiltration coefficient, dialyzer transmembrane pressure, and the time of hemodialysis. ${ }^{11}$ The results of this study showed an increase in the value of Ret$\mathrm{He}$ before and after hemodialysis so that the Ret-He examination should be done before hemodialysis because ultrafiltration during hemodialysis is affected by the Ret-He value.

\section{CONCLUSION AND SUGGESTION}

There was a significant difference in the value of Ret-He prior and after hemodialysis with UF $<2 \mathrm{~L}$. There were no significant differences in the value of Ret-He prior and after hemodialysis with UF $\geq 2 \mathrm{~L}$, and there was a significant increase in the value of Ret-He with UF $<2 \mathrm{~L}$ compared to the value of RetHe with UF $\geq 2 \mathrm{~L}$.

Based on the results of this study, the Ret-He examination should be performed prior to hemodialysis because there is a significant increase in the value of Ret-He after the hemodialysis ultrafiltration process.

\section{ACKNOWLEDGMENT}

The researcher would like to thank Mrs. Atika as a statistical consultant for providing the statistical analysis on sample data so this research could be finished.

Hopefully, this research can be useful and become the input for the parties in need.

\section{REFERENCES}

1. PERNEFRI (Perhimpunan Nefrologi Indonesia). Consensus for anemia management in chronic disease, 2011; 3-25.

2. Wirawan R. Kandungan hemoglobin retikulosit pada penderita gagal ginjal kronik dengan hemodialisis. Jakarta, Pendidikan Berkesinambungan Patologi Klinik, 2018; 265-271.

3. KDIGO (Kidney Disease Improving Global Outcomes). Clinical practice guideline for anemia in chronic kidney disease. Kidney Int Suppl, 2012; 292-298.

4. NKF-KDOQI (The National Kidney Foundation-Kidney Disease Outcomes Quality Initiative). Clinical practice guidelines and clinical recommendations for anemia in chronic kidney disease. American Journal of Kidney Disease, 2006; 28-70.

5. Dalimunthe NN, Lubis AR. Usefulness of reticulocyte hemoglobin equivalent in management of regular hemodialysis patients with iron deficiency anemia. Journal of Internal Medicine, 2016; 31-36. 
6. Urrechaga E, Borque L, Escanero JF. Assessing iron status in CKD patients: New laboratory parameters. Chronic Kidney Disease, 2012; 225-250.

7. Assimon MM, Flythe JE. Rapid ultrafiltration rates and outcomes among hemodialysis patients: Re-examining the evidence base. Current opinion in nephrology and hypertension. Wolters Kluwer Health Inc., 2015; 1062-4821.

8. Buttarello $M$, Pajola $R$, Novello $E$, Rebeschini $M$, Cantaro $\mathrm{S}$, et al. Diagnosis of iron deficiency in patients undergoing hemodialysis. American Journal of Clinical Pathology, 2010; 949-954.
9. Torino ABB, Gilberti MFP, da Costa E, de Lima GAF, Grotto HZF. Evaluation of red cell and reticulocyte parameters as indicative of iron deficiency in patients with anemia of chronic disease. Brazilian Journal of Hematology and Hemotherapy, 2014; 424-429.

10. Franck S, Linssen J, Messinger M, Thomas L. Potential utility of ret- $Y$ in the diagnosis of iron restricted erythropoiesis. Clinical Chemistry, 2004; 1240-1242.

11. Ficheux A, Ronco C, Brunet $P$, Argiles $A$. The ultrafiltration coefficient: This old 'grand inconnu' in dialysis. Nephrology Dialysis Transplant, 2015; 204-208. 